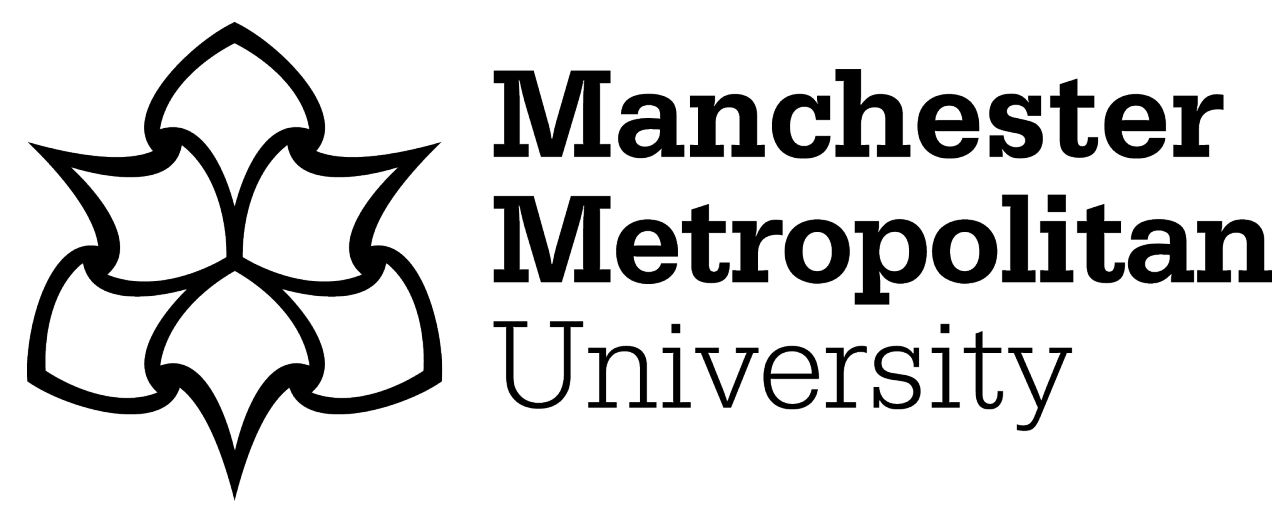

De Silva, RKJ, Rupasinghe, TD and Apeagyei, P (2018) A collaborative apparel new product development process model using virtual reality and augmented reality technologies as enablers. International Journal of Fashion Design, Technology and Education, 12 (1). pp. 1-11. ISSN 1754-3266

Downloaded from: https://e-space.mmu.ac.uk/620425/

Version: Accepted Version

Publisher: Taylor \& Francis

DOI: https://doi.org/10.1080/17543266.2018.1462858

Please cite the published version 


\title{
A collaborative apparel new product development process model using virtual reality and augmented reality technologies as enablers
}

\author{
R. K. J. De Silva ${ }^{a}$, T. D. Rupasinghe ${ }^{b}$ and P. Apeagyei ${ }^{c}$ \\ ${ }^{\mathrm{a} D e p a r t m e n t}$ of Textile \& Clothing Technology, University of Moratuwa, Moratuwa, Sri Lanka; ${ }^{\mathrm{b}}$ Department of Industrial Management, \\ University of Kelaniya, Kelaniya, Sri Lanka; ' $M a n c h e s t e r$ Fashion Institute, Manchester Metropolitan University, Manchester, UK
}

ABSTRACT

This study presents a collaborative new product development (NPD) process model that accommodates different perspectives of stakeholders in an apparel value chain and expedites robust new product outcomes. Advanced technologies are demanded to establish such collaborative NPD process models. Virtual reality (VR) and augmented reality (AR) technologies have become prominent in product realisation during this process, to evaluate multiple alternatives. The study proposes a twofold approach where, in the first phase, a qualitative study was carried out to evaluate the viewpoint of value stream collaborators to study the potential opportunities and limitations of applying VR and AR in NPD process. In the second phase, a quantitative study was carried out to assess the apparel consumers' awareness on VR or AR applications, perceptions on such technologies, and intention to use such technologies in the context of apparel business. Data collection consisted of 10 in-depth interviews with experts in the industry and 94 survey responses from apparel consumers in the United Kingdom. It is concluded that VR and AR technologies will be enablers for NPD's success in the apparel industry in providing quick responses to consumers to enhance the performance of the new products.
ARTICLE HISTORY

Received 3 January 2018

Accepted 1 April 2018

\section{KEYWORDS}

Apparel industry; augmented reality; new product

development; virtual reality

\section{Introduction}

Consumer demands for apparel are ever changing as they urge customised and personalised fashion at their earliest convenience. Also, consumers constantly expect new product experience at competitive prices. It is apparent that, emerging technologies have challenged the manufacturing paradigm of mass volume production. Therefore, mass customisation has been considered as important in order to design products to customer's requests, inferring that customers themselves are able to select basic design types and can determine the style and materials to a certain degree (Eckert, Wynn, Clarkson, \& Black, 2008). Mass customisation models expedite product differentiation to cater diversified needs of the consumer (Senanayake \& Little, 2010). Mass customisation of products, demands collaboration within value stream partners from design to manufacturing with customer, and to share the ideas and solutions to evaluate products development (Hren \& Jezernik, 2008). In this intricate nature of the business, sequential approach of new product development (NPD) activities alone does not contribute for sustainable growth of the business. Conversely, collaborative atmosphere will encourage joint partners to produce a number of ideas, though proper mechanism should be established to optimise the results. At present, integration of both virtual reality (VR) and augmented reality (AR) in applied product development is limited; and for the apparel industry application of such concept is in maiden stages. This study sought to devise a collaborative NPD process enabled VR and AR to facilitate relevant partners to work in the same platform within apparel; thereby contributing to early studies of such application in this area.

Consumer interaction, personalisation and product visualisation have been deemed as vital to the successful implementation of digital technologies to meet dynamic needs of the consumer (Apeagyei, 2010). Digital technologies stand to enhance product development capabilities in apparel manufacturing in response to clothing needs that have become personalised in terms of aesthetics and functionality; out of which the virtual and AR technologies reveal potential applications in apparel, similar to other industries.

Previous studies have moreover presented the importance of customer involvement in new product initiation and intimate collaboration between end user and innovator, as these lead to successful innovations (Chesbrough, 2003). Su, Chen, and Sha (2006) states that 
customer knowledge is indispensable for developing innovative products. VR technologies are used in manufacturing industries for early decision-making based on the virtual products, and are simulated in the virtual environments (VEs). VR tools that are robust and reliable have been urged by the apparel industrialists to cater for growing consumer demands. AR applications become popular at the point of purchase or whenever people need informational support of the product or service.

VR technologies offer greater advancement in diverse areas of manufacturing, tourism, entertainment, education and retail marketing; however, there are limited applications in the apparel industry (Walter, Kartsounis, \& Carosio, 2009). In spite of this, AR-based fashion mirror, VR fashion shows and retail apparel business using virtual avatar have become popular.

Many VR and AR related applications can be experienced in some other innovative industries; for an example, IKEA (the Swedish home furnishings retailer) use VR to realise their product ideas in their early concept development phases, marketing and promotional purposes. IKEA provides virtual shop visits with semantic product information with visualisation to their customers. Such platforms enable the user to walk through the virtual shop and choose products with a better understanding of the product (Kleinermann, Troyer, Romero, Pellens, \& Bille, 2005).

AR is widely available as mobile devices, and creates interface that explores new ways for interaction between actual and virtual world at the same time. For an example, luxury watch brand 'Tissot' has joined with Selfridges to create AR-based mirror-like display that tracks customer feedback online for variety of its product aesthetics and functional attributes [online]. 'Starbucks' introduced a mobile application to their customers to animate their coffee cups for holiday season (Justin, 2012). 'LEGO' implements AR kiosks and product demonstrations to enable more product visualisations to their customers, located in different geographical areas (Kipper \& Rampolla, 2013).

In the global apparel business, manufacturing countries tend to expand their product design and development capability, to enter into full-package manufacturing businesses (Tokatli, 2013). However, due to the lack of knowledge on overseas consumers, it is a challenge to fully accommodate their preferences. Therefore, virtual technologies can be utilised to share such knowledge required to design customised products to consumers even though they locate in different continents.

The main contributions of this paper are to provide comprehensive domain knowledge useful to VR and AR content creators to design customised applications within the context of apparel industry and to investigate the applicability of VR and AR in collaborative NPD environment. In doing so, the study sought to contribute to literature in the following aspects: (1) explore potential opportunities of VR and AR experience in apparel while providing interactive experience to internal NPD expertise and qualified product users; (2) examine limitations of applying VR/AR tools and to discuss desired experiences related to such applications, and (3) explore consumer perception on applicability of VR and AR in collaborative NPD processes of contributing consumers as a co-developers.

Customer engagement from idea generation to product validation has been identified as an integral part in collaborative product development models. This study was carried out in two parallel phases to analyse two different perspectives; that is the viewpoint of apparel value chain partners, and consumers on applicability of collaborative NPD process model enabled VR and AR.

Firstly, a qualitative study was planned to explore novel opportunities and limitations of applicability of VR and AR in apparel NPD process. Then a quantitative study was conducted to explore consumer readiness to adopt AR or VR interface in apparel buying and also interacting with product developers in designing and developing own clothing. Consumers play a vital role in future NPD processes by being an information source and through a more active form of customer involvement as co-developers (Cui \& Wu, 2017). The main idea of the quantitative study was to model consumer engagement into the VR-based apparel product development process. This study represents a theoretical basis for subject expertise and serves as a guide for developing novel apparel product development systems with appropriate computer-enabled tools, in order to optimise NPD cycles.

It seeks to provide a broader perspective of NPD to value stream partners and consumers, in developing collaborative NPD process models enabled with VR and AR.

\section{Literature review}

\subsection{Collaborative product development model}

The study characterises two distinctive groups of collaborators in apparel NPD process; namely the NPD experts in the apparel value chain and the end-product users. In global apparel supply chain, design and development functions are often carried out in developed countries whilst manufacturing takes place in the developing countries. Nevertheless, full-package production models are encouraged in those developing economies which would enable them to both expand their manufacturing 
capability while producing higher value-added products (Bair \& Gereffi, 2003). Collaborative product development models are required to reduce product development cycle times (Hren \& Jezernik, 2008). Conversely, collaborative process models are complicated in nature when handing extensive amount of information and number of product iterations. Therefore, appropriate state-ofthe-art technologies are needed when operationalising collaborative NPD models to incorporate different ideas into one product concept (Jimeno \& Puerta, 2007).

Consumer involvement in NPD process has been identified as a positive drive, as in this new approach, it allows customers to actively engage in the NPD process as co-developers with the internal expertise (Fang, 2008). Customer inputs lead to generate creative ideas (Nishikawa, Schreier, \& Ogawa, 2013), improve product variety (Al-Zu'bi \& Tsinopoulos, 2012) and enhance product performance (Lau, Tang, \& Yam, 2010); therefore new technologies have the potential to greatly enhance the connectivity between customers and manufacturers in an economical way (Nambisan, 2002).

Previous research reveals that the success of NPD depends on a range of knowledge inputs contributing to a combination of diverse perspectives which further inspire novel insights (Luca \& Atuahene-Gima, 2007). Furthermore, the development of innovative products requires openness and flexibility in the NPD process, capability to manipulate different perspectives as well as control direction to ensure novel insights are effectively integrated and implemented to generate product solutions (Chiang \& Hung, 2014). As such, the sharing of diverse knowledge among NPD value chain partners and customers will integrate and accelerate the new idea generation process (Nambisan, 2002).

\subsection{Virtual reality, virtual prototype and virtual environment}

An overview of virtual aspects is stated here for a better understanding within this research context. Virtual prototypes, VR and VE; are often applied in different ways. VR may be defined as the use of a computer-generated 3D environment called a VE that a user can navigate and possibly interact with, furthermore, it facilitates real-time simulations of one or more of the user's five senses (Gutiérrez, Vexo, \& Thalmann, 2008). VR-based systems are becoming popular as they enable advanced forms of human-computer interaction based on a wide range of inputs, such as voice recognition and movement tracking, and an even wider range of outputs, such as advanced graphics, auditory displays and haptic interfaces (Seth, Vance, \& Oliver, 2011). VR can be applied in different domains of manufacturing, such as design, prototyping, assembly and maintenance (Ong \& Nee, 2004).

Virtual prototype is a computer simulation of a physical product that can be tested through design to manufacturing cycle (Ottosson, 2010). Virtual prototyping may be used in apparel designing and developments at initial phases of product developments. There is currently limited knowledge regarding limitations in applying correct $3 \mathrm{D}$ tools in the systematic NPD process. The NPD process also needs to be improved and be equipped with right VR tools to respond to dynamic needs of the future customer. This would improve the conventional product development set up to a more advance NPD mechanism.

\section{Methodology}

A mixed methods approach was adopted to integrate multiple perspectives and to relate complete understandings (Creswell, 2007) of the consumer engaged NPD process. A qualitative approach was utilised to brainstorm the expertise to gather deep insights on the NPD and feasibility of VR or AR tools in respective of apparel NPD process stages. As per Flynn, Sakakibara, Schroeder, Bates, and Flynn (1990), qualitative methods are more appropriate to recognise variables and define parameters in developing models and simulation systems in operations management or industrial engineering fields. A quantitative approach, on the other hand, was utilised to collect consumer viewpoints. However as VR and AR are emerging applications, there was not much experience established to comment on them in depth.

The qualitative data collection was based on 10 indepth interviews of apparel product development expertise in the United Kingdom representing main NPD activities in the apparel value chain. The quantitative data collection was based on 94 responses from apparel consumers representing 11 nationalities residing in the United Kingdom. The qualitative part of the study was dedicated to the exploration of current drawbacks of apparel NPD process, to what extent VR is applied in the product development process and indicate potential opportunities of VR and AR in apparel NPD. Figure 1 illustrates the research design of the qualitative research part of this paper. In Figure 1, NPD activities were listed according to the findings of the previous study of De Silva and Rupasinghe (2018). There were four key areas identified as 'Potential Tech Interventions within the NPD' illustrated in the Figure 1. Subsequently, qualitative data findings were expounded using Table 2.

The quantitative study has been conducted to review the applicability of VR/AR among the consumers, using research constructs derived from Technology 
Acceptance Model (TAM) theory (Davis, 1989). Finally, both results were integrated to devise a collaborative NPD process model.

\subsection{Qualitative data collection and analysis}

Snowball sampling methods have been utilised to recruit an appropriate sample of academics and practitioners and more specifically, the selected academics were qualified with at least 10 years of working experience in the similar context. The participants were selected from seven key areas (see Table 2) of the apparel value chain which are more relevant to the NPD functionalities. The participants' profiles include; Global Materials Commercialisation Manager, Regional Director - Europe in Innovation Brand X, Senior Lecturer - Fashion Technology/CAD, Senior Lecturer Fashion Business, Lecturer - Product Development, Lecturer - Virtual Prototyping, Senior Lecturer - Textile Technology, Reader - Production Technology, Senior Lecturer - Fashion and Textile Technology, Lecturer - Fashion Marketing. Each interview took a form of semi-structured and face-to-face and was conducted for at least one hour during the period of October 2016 to January 2017. Subsequently, each interview was transcribed and systematically encrypted into RQDA software (Huang, 2010). Thematic analysis has been performed to develop code structures according to the research questions. Subsequently, results were tabulated as a form of reflective writing to summarise and conceptualise potential opportunities and limitations persist with VR and AR (see Table 2).

\subsection{Quantitative data collection and analysis}

Quantitative data were collected using an online survey distributed among convenience sample. Survey instrument was created in BOS online survey tool and pilot study has been carried out with 8 researchers in the similar field of study. After that, the link to the questionnaire was emailed to the selected participants including brief introduction of the study. Mainly, the undergraduate and postgraduate students with the similar academic background have been selected for the study. In addition, the survey link has been emailed to industry workers considering their understanding of the subject. Seemingly, VR or AR awareness of the respondents also was considered when selecting the proper channel to forward the survey link. A brief introduction to the study was given in the first page of the questionnaire. Ethical approval and informed consent also were emailed together with the survey link. In addition, there were three images of VR and AR applications in apparel business included at the beginning of the questionnaire for better understanding of the scenario. The data collection has been carried out during a three-month period; from Jan 2017 to Mar 2017. Table 1 describes the sample characteristics of the study population of 94 .

Virtual technologies that are emerging could not expect much experience from the consumers due to limited availability of such opportunities yet. Therefore, an exploratory type short questionnaire has been developed consists of 10 closed-ended questions and one openended question at the end. Consumer awareness of VR/AR and perceived usefulness were evaluated using

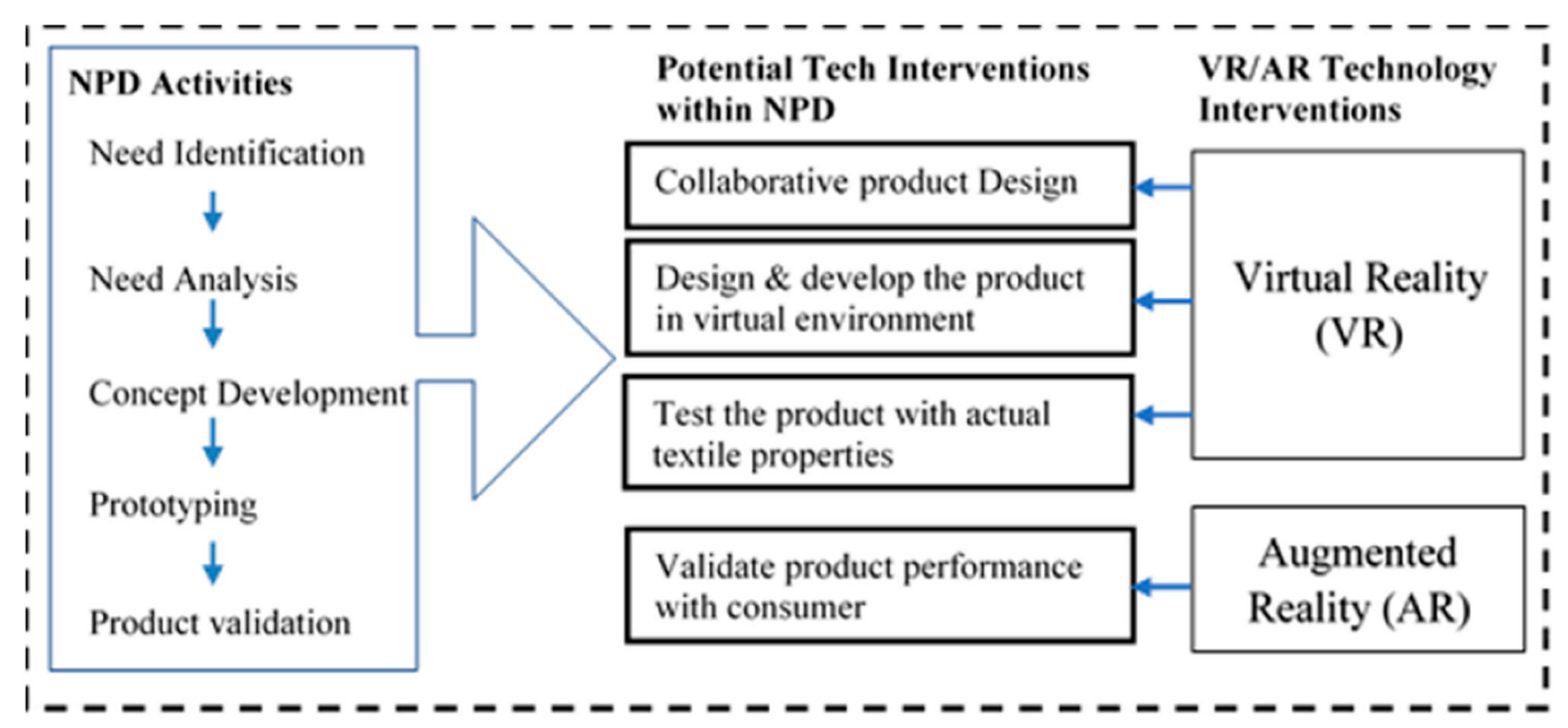

Figure 1. Qualitative research approach. 
Table 1. Sample characteristics of the survey.

\begin{tabular}{lc}
\hline Characteristic & Percentage \\
\hline Age & \\
$18-25$ & 16 \\
$26-35$ & 45 \\
$36-45$ & 32 \\
$46-55$ & 7 \\
Gender & \\
Male & 51 \\
Female & 49 \\
Education & \\
Ph.D. or Masters' Degree & 63 \\
Completed some postgraduate & 12 \\
Bachelor's Degree & 25 \\
Ethnicity & \\
British & 30 \\
Scottish/ English/ Welsh & 14 \\
Arab & 10 \\
Indian & 9 \\
Sri Lankan & 18 \\
African & 7 \\
France & 5 \\
Chinese & 4 \\
Mixed ethnic and others & 3 \\
\hline
\end{tabular}

closed-ended questions and analysed the results using an analytical decision-making process shown in Figure 2.

The closed-ended questions were planned to identify consumer awareness of VR/AR, and perceived usefulness of such tools while the open-ended question was designed to measure the intention of using such technology in the user perspective. Analytical network process (ANP) and decision modelling have been utilised for this quantitative part of the study. In doing so, this
ANP diagram (see Figure 2) represents the two research constructs, consumer awareness of VR/AR and perceived usefulness with respect to their current methods of information receipt. The group of consumers who received new product ideas from fashion blogs/social media and retail websites were considered as early adopters of VR/AR. This group of consumers was denoted as 'sources of digital technology based' according to the ways they gather information on new product ideas. In addition, the other group of consumers were denoted as 'sources of real environment based' according to their ways of information gathering on the same. The awareness of VR/AR and perceived usefulness also divided into two clusters, respectively. The relationships were defined to characterise the awareness of VR/AR and perceived usefulness of them among apparel consumers.

\section{Results}

\subsection{Qualitative evidence}

The focus of this study is to give a background to VR and AR intervention in NPD process in the context of apparel industry. New products are demanded for sustainable growth of the apparel business. Effective use of $\mathrm{CAD}^{\circ}$ systems and 3D clothing simulation facilitates short product development cycles. During the study, NPD process activities were subjected to rigour analysis with the

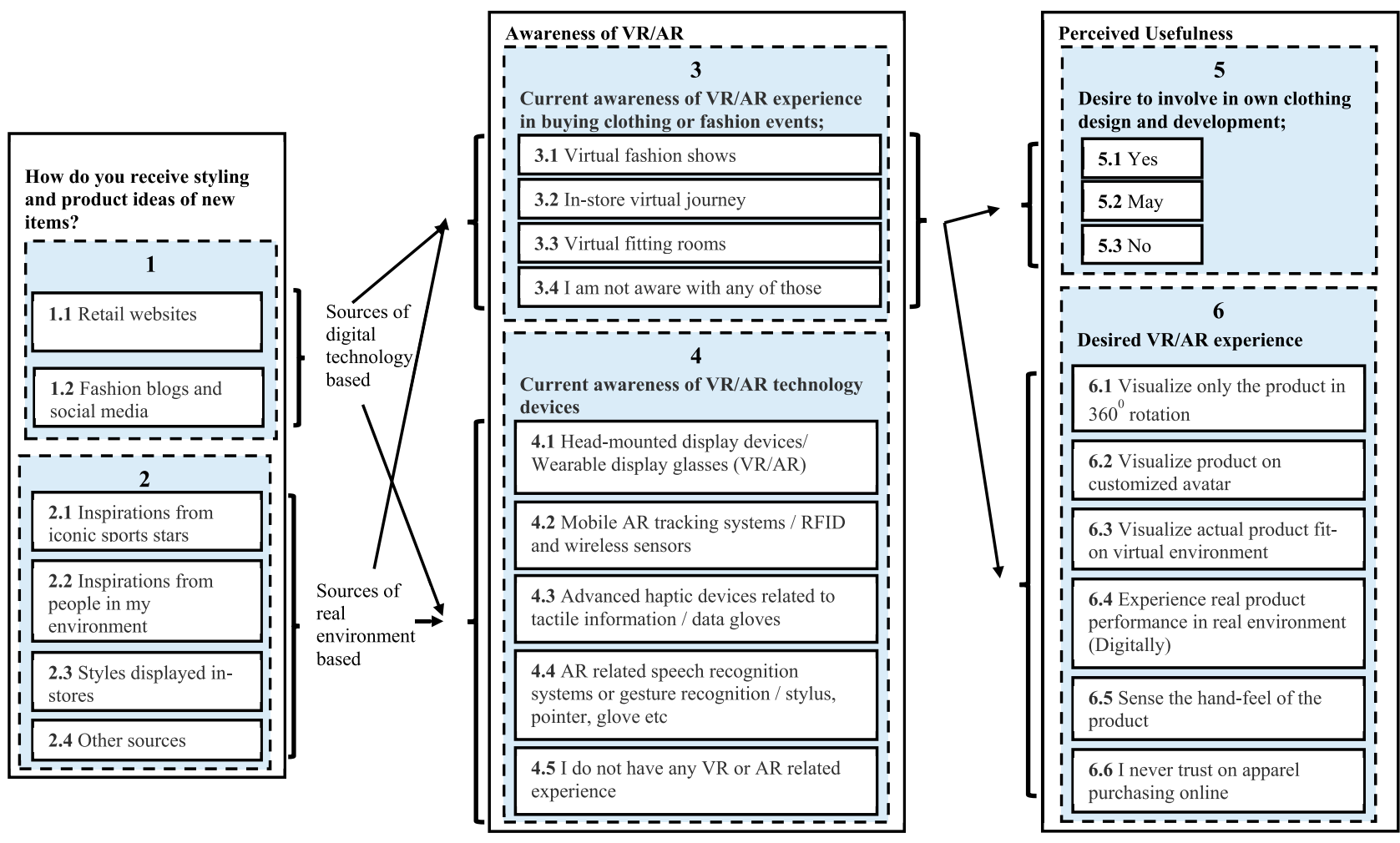

Figure 2. Quantitative research approach - ANP for decision path. 
Table 2. Qualitative data analysis - potential opportunities and limitations of VR and AR in NPD process.

Respondents represent value chain

Fashion marketing

Apparel business analyst

$R \& D$

Fashion technology

Material expertise

Product developer

VR/AR-based opportunities

Limitations of adapting virtual technologies

Trend analysis and forecasting using VR

Systematic market research with rigour trend analysis will direct for NPD success. Market analysis can be done by displaying a large number of virtual products online and receive feedback to which products show highest demand. Virtual fashion shows, exhibitions will be good opportunity to expose to fashion markets even from far-away destinations.

\section{Connect with consumer}

Complex market structures including multi-channel and omnichannel positions have been established in apparel business therefore online connectivity with the consumers are characterised. Inevitably, VR products and immersive experience will be obliged to apparel manufacturers who are located in far-away countries to obtain a real idea on consumers and life styles.

Promotional purposes

Virtual sampling can be used for promotional purposes to alert upcoming product concepts and range using VR and web technology.

Mass customisation

In general people inspire fashion trends from similar peer groups to show possessiveness to that part of the community, however they look for uniqueness when they actually buy. Virtual prototyping facilitates to customise product solutions to make sure personalised product experience.

Better communication within the apparel value chain

VR based NPD system can be effectively used for collaborative NPD model, apparel value chain partners can be involved in the holistic process to improve the NPD success and mitigate the NPD risk.

Generate ideas for product initiation

Lead users, in other words, branded consumers can be involved in NPD process using AR, virtual trials can be done even for scanned real body measurements and let consumers to feedback on the styling. (For an example Virtual Outfits)

Alleviate design functionality

Consumer expects fashion ideas for one whole outfit with footwear and accessories as one range. In this purpose, VR can be used by fashion designers to realise more design ideas using virtual outfits for decision-making. In addition, those outfits can be realised in VEs to visualise products during the conceptual design phase.

Simulate the products to assess aesthetic characteristics

3D CAD is widely used to get the aesthetic assessments of a product rather functional. Furthermore, advanced 3D simulation software indicates relatively right fit-on using tension maps, stretch maps and ease maps for certain garments even with the end use simulation such as cycling, running, outdoor activities.

Right product at right time

Products must be available for right time as clothing designs targets for buying cycles. VR facilitate to reduce physical sample iterations and virtual products can be used for early decision-making process.

Fit trials for different sizing

$3 \mathrm{D}$ clothing simulation using scalable avatars will reduce the risks of developing products for larger sizes as live fit process for large population is challenging.

Test feasible manufacturing options and product performance Test different fasteners options, print placements and other production variables. Clothing fit assessments for different size avatars to test the pattern grading.

Conduct training from remote locations

Larger order quantities are divided to several manufacturing countries; in that case, VR can be used to conduct training and demonstrations on product assembly to maintain standards.
People would like to get real experience of a fashion show at the locations. Most significantly young fashion-oriented customers often use social media and difficult to reach aging population through information technologies.

Low-cost manufacturers are reluctant to invest such advanced virtual technologies as capital investment is high at the beginning. In addition, Textiles are not rigid, difficult to feel the drape and exact fit in a VR tool, and currently highest product returns of $20 \%$ from apparel category. Software needs to be upgraded in this aspect.

Some colours and style features are difficult to visualise on screens especially black colour.

Silhouette designs mainly depend on the social, cultural, demographic factors of the consumers, so longitudinal studies are preferred to analyse real consumer taste.

Collaborative product development mechanism incorporated with virtual technology needs to be established to get the optimum benefit in NPD process.

Open innovation would spread out the consumer voice ubiquitously, that would obstruct $R \& D$ process of the organisation.

Fashion designers seek necessary training on 3D clothing simulations on VEs. Participants highlighted the need of user-friendliness of such software systems.

Current virtual prototyping software is not intelligent enough to indicate the exact fit and performance of the garments, for body compression garments, especially made out of several layers, very stretchy materials and complicated constructions. The main problem is the virtual mannequin is rigid that does not reflect the real body.

Respondents expressed their own experiences of system incompatibility between buyer end and the manufacturer end.

Virtual mannequin does not reflect the real body even though measurements are fed to the system.

Complicated rendering process and simulation for functional clothing.

Technology maturity level and availability of such technology in different countries. 
Table 2. Continued.

\begin{tabular}{|c|c|c|}
\hline $\begin{array}{l}\text { Respondents represent } \\
\text { value chain }\end{array}$ & VR/AR-based opportunities & Limitations of adapting virtual technologies \\
\hline \multirow{3}{*}{$\begin{array}{l}\text { CAD/3D prototyping } \\
\text { expertise }\end{array}$} & $3 D C A D$ facilitate rapid prototyping & \\
\hline & $\begin{array}{l}\text { CAD patterns and } 3 D \text { presentations are basic levels for } \\
\text { advanced VR/AR tools. These systems are part of } \\
\text { e-commerce hence large amount of data can be stored for } \\
\text { less cost. Also align with sustainable business models. } \\
\text { Verify patterns, styling, embellishment placements }\end{array}$ & $\begin{array}{l}\text { Software needs to be upgraded to provide exact fits for } \\
\text { different material properties. }\end{array}$ \\
\hline & $\begin{array}{l}\text { Apart from original pattern creation and prototyping, } \\
\text { amendments can be tested in a short period of times using } \\
\text { 3D clothing simulation software. }\end{array}$ & $\begin{array}{l}\text { Skill deficiency of computerised system users in the apparel } \\
\text { organisations is one of the major barriers in system. } \\
\text { Therefore, adequate training is demanded to get the } \\
\text { optimum benefit of these systems. }\end{array}$ \\
\hline
\end{tabular}

drawbacks of digital applications. Existing digital technologies were highlighted with the limitations of adopting them in apparel industry. Collaborative product development model is demanded by the apparel industrialists with the aid of virtual simulation technologies. VR ideas are more related to virtual prototyping to simulate the product or could be used to evaluate the performance evaluation of the product in the VE. VR could be used to test blue sky ideas even it is not necessary to develop the complete product at that stage. In majority of the cases, virtual prototype was used only to assess the aesthetic attributes of the product and not to assess the performance attributes. Therefore, 3D clothing simulation systems need to be further developed to assess the functional aspects of the products and also to test the manufacturability. In future NPD processes, technical specifications of the product will also have to be delivered as a VR file to receive real-time information to the product manufacturer. Furthermore, there are AR technologies which can be incorporated to the future NPD process model, in favour of consumer connectivity, $\mathrm{AR}$ can be used to create VE to create immersive environments, and design interface to intervene product design and development to provide truly customised products. That open innovation approach will minimise NPD failure and it reduces the total NPD cost.

Every participant in the field highlighted the material constraints when applying VR into apparel. It is believed perfect simulation could not be achieved with the textile materials where the existing $3 \mathrm{D}$ clothing simulation software needs to be improved. For an example, design, manufacturing, maintenance like most of the operations in the automobile industry are simulated using VR. In this case, simulating the garment construction would be a real challenge. Human perceptual issues would be a matter in decision-making in the apparel product development model, as developers used to take decisions based on haptic feedback. In this circumstance, the relevant stakeholder parties are anticipated to change their minds to get used to advanced technologies.
Importantly, apparel sizing needs to be thoroughly considered in 2D CAD pattern developments as it will directly affect the right fit-on. Even though Product Lifecycle Management systems are available in the apparel industry, these were not integrated into the prototyping software systems which are in the product development centres. That limitation exists in the sharing of real-time technical information which will restrict the NPD success. Table 2 summarises the reflections of those interview quotes made by the NPD expertise. In addition, consumer connectivity throughout the NPD process will reduce the NPD risks and NPD cycle time. AR technologies can be applied to develop interactive tools to consumers to engage with the product designers and the development teams.

\subsection{Quantitative evidence}

This part of the analysis was carried out to complete the third objective of the study. Hereafter, this study measures consumer perceived value of VR and AR in new apparel product development process and explores how the consumer can be involved into the process. The TAM theory was utilised for this part of the study to analyse individual's acceptance of technology using the three constructs described in the TAM model. Namely; consumer awareness, perceived usefulness and intention of using both VR and AR. The first two research constructs were analysed quantitatively based on Figure 2 and followed by pie charts in Table 3 and intention to use was analysed based on the open-ended question in the survey. TAM is a versatile theoretical model adopted in different contexts to understand and explain the acceptance of new technologies (King \& $\mathrm{He}, 2006)$. As this study focused on VR and AR technologies, certain elements of TAM can be utilised to understand perceived usefulness, intention to use and attitude towards usage of VR technologies (Venkatesh, 2000).

The quantitative analysis was carried out by utilising a systemic multi-attribute analytical technique, known as the ANP (Saaty, 2008). In Figure 2, the first cluster 
Table 3. Quantitative data analysis - consumer awareness and perceived usefulness of VR or AR.

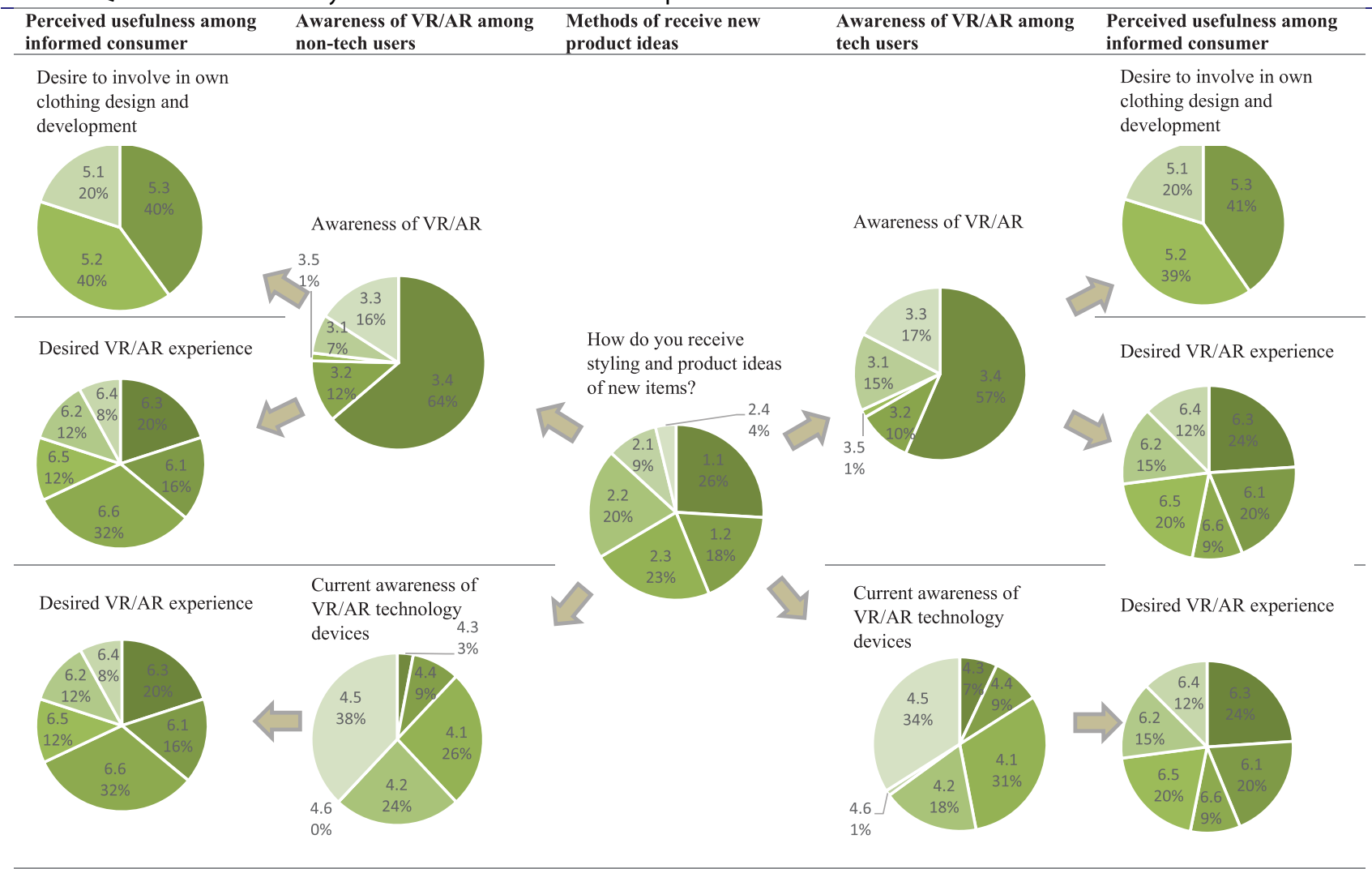

depicts how consumer receives styling and product ideas of new items, and then it relates to their awareness of VR/AR applications and technology devices, finally, it relates to the perceived useful of the VR/AR according to the consumer perspective.

\subsection{Consumer awareness and perceived usefulness of VR or AR}

The centre pie chart depicts how consumer receives styling and product ideas of new items currently. Then the right-hand side from the centre pie chart, depicts how the decision evolved from cluster 1. Accordingly, the left-hand side depicts the decision evolved from cluster 2 (see Table 3).

There were $44 \%$ of consumers who used digital technologies to receive new product information. In that consumer segments, there were $57 \%$ of consumers were not aware with any of apparel-related VR/AR experience. In this consumer segment, the highest percentage of them $(24 \%)$ wants to visualise actual product in VE and experience an accurate fit-on according to customised measurements. On the other hand, the very few of them (9\%) mentioned that they never trust virtual technologies in buying apparel. In this consumer segment, there were $20 \%$ of consumers were desired to be involved in own clothing design and development. In addition, approximately, $39 \%$ of consumers did not confirm their acceptance for the adaptation, though they will be responded positively if they were provided with the correct tool. Moreover, 34\% of this consumer segment did not have AR/VR related experience. However, the highest percentage of consumers (24\%) wanted actual fit-on of the product shown in an appropriate VE.

On the other hand, there were $56 \%$ of consumers who received new product ideas from real environment. In that consumer segments, there were $64 \%$ of consumers were not aware with any of apparel-related VR/AR experience. Furthermore, there were $32 \%$ of same group of consumers never trust on VR/AR according to their current experience. Apart from them, next highest percentage wants to visualise actual product in VE and experience an accurate fit-on according to customised measurements. In addition, in the same group of consumers, there were $20 \%$ of consumers were desired to be involved in own clothing design and development. In addition, approximately, $40 \%$ of consumers did not confirm their acceptance for the adaptation. Furthermore, there were $38 \%$ of this consumer segment did not have $\mathrm{AR} / \mathrm{VR}$ related experience. In the same 
consumer group, there were $32 \%$ of consumers mentioned that they never trust on virtual technologies in apparel buying. Although, the next highest group of consumers wanted actual fit-on of the product shown in an appropriate VE. Hitherto, VR/AR technologies have not immersed in the apparel customers, therefore enormous opportunities are ahead to discover in recent future.

\subsection{Intention to use such technology - qualitative finding of the questionnaire survey}

Intention to use such technology has been measured using an open-ended question to inquire consumer opinion on VR or AR experience which consumer would like to engage in reviewing apparel. Consumer expects actual fit and styling of the product followed by their exact body measurements and shape. A female Chinese consumer of Age 36-45 commented, 'I would like to see real fit and style on a figure with my sizing'. A number of websites and mobile apps display product lines and promote online purchasing of clothing. However, they lack the providing of real fit of the product according to the human body anthropometry. In addition, consumer expects virtual fit of the product in the VE to experience the clothing fit with the end use of such product. A Sri Lankan doctoral-researcher of age 26-35 commented, 'It would be interesting to interact with the garment by customising the features and get the real-time experience on the fit-on and performance'. Some footwear retailers provide facility to select their own footwear design and some product characteristics using their websites, for an example, NIKE facilitate their consumers to select their own shoe design in their 'NIKEiD' website (http:// nikeid.nike.com). A British male consumer of age 36-45 years expected, 'reasonable drape of the product in $360^{\circ}$ angle and fit the garment on my body'. Furthermore, consumers expect tactile sensations of apparels through AR experience. Literally, they will take final decision with evaluating the product cost, a consumer mentioned that, 'I would never spend more than $£ 20$ on clothes if I do not have chance to touch'. The opinion of a Scottish consumer of age 46-55 years was to experience such haptic perception when buying clothing. He mentioned his idea as, 'Visualising the actual product on individual's 3D picture and sensing of the product's hand feel'. That statement reflects consumer wants AR experience also with the haptic feedback of an apparel. A Chinese consumer of age 26-35 years mentioned her expectation on a virtual store similar to real shopping destination, 'It should be as same as shopping at a store'. Significant number of respondents highlighted their preference on virtual shopping experience to save unnecessary time spending at a store. Moreover, consumers anticipate 'Realistic representation of drape, colour and fit' of the product highlighted a British consumer age of 36-45 years in the survey. In addition, people expect other users' experience to share their knowledge on the system. A British consumer of age 26-35, showed future opportunities of VR and AR with this statement in his response, 'VR or AR might be the key to the development of personalised clothing in the future'.

\section{Discussion}

Most of the apparel organisations endure manual methods of NPDs yet, mainly due to the lack of seamless method for data exchange among value chain partners. Existing NPD models require several physical prototypes for decision-making adversely effect on wastage of the organisational resources. Currently, industry could not achieve optimum benefit from CAD applications in product development as each system is working alone, they do not interact with each other to keep the consistency during the process.

In addition, even though consumer involved NPD model was identified as important, there was no mechanism established to link consumer into the NPD process of the organisation. With the increased popularisation of online retail businesses, VR and AR platforms are demanded to establish the connectivity between the consumer and the manufacturer. This study intended to fill this void by proposing VR and AR-enabled NPD process.

Consumers request VE which consumer explicitly would be able to immerse and experience a strong sense of presence; immersion is the striking characteristic of the VE. The ergonomic and the aesthetic features of the product can be evaluated by incorporating the user in the VE. Such environment provides the platform to design and manufacture extremely customised products. The evidence would appear to suggest that though VR and AR technology is available in the market, apparel technologists are not psychologically prepared to accept those for their real product development functionality. VR enabled processes will facilitate collaborative product development by the designers, material developer, garment technologist and customer will be able to work in the same platform and they will be able to share their feedback using the same. That model will be able to mitigate NPD risks as well as improve the NPD cycle times.

An online survey was conducted to receive consumer perspective on VR/AR tools and devices in apparel context in three aspects derived from TAM theory. Consumer awareness of VR/AR technologies or applications and perceived usefulness of them were measured quantitatively and intended use was evaluated qualitatively. 
According to the survey results, half of the total population inspires new product ideas by seeing the physical products such as from styles displayed in-stores, inspirations from iconic sports starts, inspirations from people in their environment or other sources. Out of this population, $57 \%$ of consumers were not aware with any VR/AR related experience in buying clothing or fashion events. That interprets VR/AR in apparel context is emerging, not much applications are available to penetrate to a wide range of consumers yet. Head mounted display devices were the popular device among participants compared to other given technologies or devices. There were $20 \%$ of consumers accepted to involve in own clothing design and developments using digital technologies while another $41 \%$ of consumers also showed their desire in collaborative clothing design and development model.

Also, there were $39 \%$ of consumers who did not agree on participating in apparel design and development using digital technologies, out of this group, there were $18 \%$ of consumers from this group who never trusted on apparel purchasing online. Importantly, consumers who were acquainted with VR/AR applications in apparel context were further analysed to evaluate their desired VR/AR experience according to their perception. In this segment, the majority of the consumers would like to visualise actual product fit-on in VE. Apparently, they need correct fit-on, therefore apparel sizing would be more important in developing such VR/AR tool. There were $17 \%$ of the consumers who wanted to sense the hand feel of the product. Moreover, intention to use such technology was assessed using an open-ended question. The respondents were highlighted their prime expectation to visualise actual fit and styling of the product that follows their real body measurements and shape.

\section{Conclusion}

Most of the apparel NPD process models discussed in the literature restricts products realisation, visualisation and synchronisation within its value chain partners and customers. Many improvements are needed to establish the human-computer interaction in apparel NPD followed with a systematic process. Collaborative NPD model is demanded by the apparel industrialists with the aid of virtual simulation technologies. Consumer connectivity throughout the NPD process is more crucial that reduces the NPD risks.

In future, mass customised business models are demanded with collaborative product development effort of value stream partners and consumers. This study contributes to the literature in several aspects including; consumer involved NPD process and how it can be performed based on VR/ AR technologies. Some of the key findings can be identified as below:

- In this era, consumer expects virtual experience to design their own apparel design and development apart from buying,

- NPD team have to seek opportunities to connect with the consumer to generate novel product ideas,

- Consumer needs have to be customised in terms of virtual clothing according to their body measurements and simulate the fit-on in appropriate VE,

- A significant percentage of the consumers expect haptic feedback of the product at the point of purchase,

- More precisely, VR tools are more applicable in development stage of the product. For example, virtual prototyping,

- AR tools are applicable at the point of consumer integration. For example, concept tests and fit assessments.

Advanced virtual technologies are highly demanded. Future research needs to be conducted to develop customised VR and AR products to strengthen apparel NPD process to reduce NPD cycle time and improve consumer responsiveness. VR platforms can be used to position manufacturer and retailer much closer in the global apparel business. Effective training of existing $3 \mathrm{D}$ clothing simulation solutions to achieve accurate garment fits. VR and AR applications lay the platform to connect with the consumer in relevant NPD phases such as idea generation and product validation. Collaborative NPD approach integrates diversified perspectives amongst value stream partners and customers who are required to face such dynamic. Virtual technologies enable quick responsive NPD process in global apparel business since manufacturers are located far away from consumer base. In conclusion, this study lays the foundation on the applicability of VR \& AR as tools to have the potential to make lucrative improvement to the new apparel product development though engineered process modelling. It is contended that appropriate VR and AR-based tools are demanded both stakeholders of the NPD team and consumers to execute new ideas in NPD of apparel.

\section{Disclosure statement}

No potential conflict of interest was reported by the authors.

\section{References}

Al-Zu’bi, Z. M. F., \& Tsinopoulos, C. (2012). Suppliers versus lead users: Examining their relative impact on product 
variety. Journal of Product Innovation Management, 29(4), 667-680.

Apeagyei, P. R. (2010). Application of 3D body scanning technology to human measurement for clothing Fit. International Journal of Digital Content Technology and Its Applications, 4(7), 58-68.

Bair, J., \& Gereffi, G. (2003). Upgrading, uneven development, and jobs in the North American apparel industry. Global Networks, 3(2), 143-169.

BOS online survey tool. Retrieved from https://www. onlinesurveys.ac.uk/

Chesbrough, H. W. (2003). Open innovation: The new imperative for creating and profiting from technology. Boston, MA: Harvard Business School Press.

Chiang, Y. H., \& Hung, K. (2014). Team control mode, workers' creativity, and new product innovativeness. R\&D Management, 44(2), 124-136.

Creswell, J. W. (2007). Research design: Qualitative, quantitative and mixed method approaches (pp. 203-223). Thousand Oaks, CA: Sage.

Cui, A. S., \& Wu, F. (2017). The impact of customer involvement on new product development: Contingent and substitutive effects. Journal of Product Innovation Management, 34(1), 60-80.

Davis, F. D. (1989). Perceived usefulness, perceived ease of use, and user acceptance of information technology. MIS Quarterly, 13(3), 319.

De Silva, R. K. J., \& Rupasinghe, T. D. (2018). A new apparel product development framework for performance clothing industry. International Journal Product Development, 22 (4), 276-292.

Eckert, C. M., Wynn, D. C., Clarkson, P. J., \& Black, S. (2008, April 21-25). Process simulation to make personalisation economically viable. Proceedings of TMCE symposium, Turkey.

Fang, E. (Er). (2008). Customer participation and the trade-off between new product innovativeness and speed to market. Journal of Marketing, 72(4), 90-104.

Flynn, B. B., Sakakibara, S., Schroeder, R. G., Bates, K. A., \& Flynn, E. J. (1990). Empirical research methods in operations management. Journal of Operations Management, 9 (2), 250-284.

Gutiérrez, M. A. A., Vexo, F., \& Thalmann, D. (2008). Stepping into virtual reality. London: Springer.

Hren, G., \& Jezernik, A. (2008). A framework for collaborative product review. The International Journal of Advanced Manufacturing Technology, 42(7-8), 822-830.

Huang, R. G. (2010). RQDA: R-based qualitative data analysis: $R$ package version $0.2-1$. Retrieved from http://rqda.r-forge. r-project.org

Jimeno, A., \& Puerta, A. (2007). State of the art of the virtual reality applied to design and manufacturing processes. International Journal of Advanced Manufacturing Technology, 33(9-10), 866-874.

Justin. (2012). The benefits of augmented reality in mobile marketing. Retrieved from http://www.mobilemarketingwatch. $\mathrm{com} /$ the-benefits-of-augmented-reality-in-mobile-market ing-21047/\#
King, W. R., \& He, J. (2006). A meta-analysis of the technology acceptance model. Information \& Management, 43(6), 740-755.

Kipper, G., \& Rampolla, J. (2013). Augmented reality: An emerging technologies guide to AR. Waltham, MA: Syngress/ Elsevier.

Kleinermann, F., Troyer, O. D., Romero, M. R., Pellens, B., \& Bille, W. (2005). Designing semantic virtual reality applications. Proc. of the 2nd Intuition International Workshop, Senlis, France.

Lau, A. K. W., Tang, E., \& Yam, R. C. M. (2010). Effects of supplier and customer integration on product innovation and performance: Empirical evidence in Hong Kong manufacturers. Journal of Product Innovation Management, 27(5), 761-777.

lego_ar_studio_app - News Room - About Us LEGO.com. [online]. Retrieved from https://www.lego.com/en-us/ aboutus/news-room/2017/december/lego-ar-studio

Luca, L. M. D., \& Atuahene-Gima, K. (2007). Market knowledge dimensions and cross-functional collaboration: Examining the different routes to product innovation performance. Journal of Marketing, 71(1), 95-112.

Nambisan, S. (2002). Designing virtual customer environments for new product development: Toward a theory. The Academy of Management Review, 27(3), 392.

Nishikawa, H., Schreier, M., \& Ogawa, S. (2013). User-generated versus designer-generated products: A performance assessment at Muji. International Journal of Research in Marketing, 30(2), 160-167.

Ong, S. K., \& Nee, A. Y. C. (2004). Virtual and augmented reality applications in manufacturing. London: Springer.

Ottosson, S. (2010). Virtual reality in the product development process. Journal of Engineering Design, 13(2), 159-172.

Saaty, T. L. (2008). Decision making with the analytic hierarchy process. International Journal of Services Sciences, 1 (1), 83-98.

Senanayake, M. M., \& Little, T. J. (2010). Mass customization: Points and extent of apparel customization. Journal of Fashion Marketing and Management: An International Journal, 14(2), 282-299.

Seth, A., Vance, J. M., \& Oliver, J. H. (2011). Virtual reality for assembly methods prototyping: A review. Virtual Reality, 15 (1), 5-20.

Su, C., Chen, Y., \& Sha, D. (2006). Linking innovative product development with customer knowledge: A data-mining approach. Technovation, 26(7), 784-795.

Tokatli, N. (2013). Toward a better understanding of the apparel industry: A critique of the upgrading literature. Journal of Economic Geography, 13(6), 993-1011.

Venkatesh, V. (2000). Determinants of perceived ease of use: Integrating control, intrinsic motivation, and emotion into the technology acceptance model. Information Systems Research, 11(4), 342-365.

Virtual Outfits | A virtual fitting room to dress up your avatar. Retrieved from http://www.virtualoutfits.com/

Walter, L., Kartsounis, G., \& Carosio, S. (2009). Transforming clothing production into a demand-driven, knowledge-based, high-tech industry: The leapfrog paradigm. London: Springer. 